\title{
Aproximación a las representaciones mediáticas de la mujer
}

\author{
Trabajo de Revisión Documental
}

Dineyis Esther Arias-Mendoza ${ }^{11}$

\section{Introducción}

La representación mediática de la mujer es un tópico de interés académico en los últimos años. Investigadores en todo el mundo reconocen al entorno sociocultural, donde la comunicación y los medios de comunicación contemporáneos fungen de articuladores, como una de las variables necesarias en los procesos de construcción de realidades como el género. Es decir, nociones de ser hombre y ser mujer, se elaboran en la práctica del lenguaje, la asignación e interacción simbólica. De hecho, los estereotipos de género como orientadores sociales, "ese conjunto estructurado de creencias, compartidas dentro de una cultura, acerca de los atributos o características que poseen hombres y mujeres" (De Lemus, Moya, y Bukowski, 2008, p. 115) se consolidan y transmiten con una frecuencia mayor a través de fuentes mediáticas de indiscutible poder.

Desde la televisión, la publicidad, el cine, la radio y ahora Internet, se comunican límites, marcas, modelos y sellos sobre los géneros en un sistema de representaciones de lo femenino y lo masculino que nos ubica bajo unos parámetros establecidos. Con

${ }^{11}$ Comunicadora Social y Periodista. Magíster en Desarrollo Social. Docente investigadora - Coordinadora del Componente Socio-Humanístico, Programa de Comunicación Social y Periodismo de la Universidad Sergio Arboleda, Seccional Santa Marta, Colombia. Investigadora adscrita al grupo de investigación Comunicación y Sociedad de la misma Universidad. E-mail: dineyis.arias@usa.edu.co 
lo cual, modelos de masculinidad, como la masculinidad hegemónica, se imponen y persisten en muchos escenarios sociales como mecanismos de resistencia a la igualdad entre mujeres y hombres:

La masculinidad hegemónica continúa definiendo las actitudes y prácticas de la prevalencia del macho heterosexual. Por este tipo de masculinidad ser un hombre significa aceptar que la mujer es un objeto y este tipo de prácticas de subordinación hacia ellas, así como la derogación de aquellos hombres que adoptan una base de igualdad con las mujeres (Weitzer y Kubrin, 2009, p. 5).

En esta revisión documental fue evidente que, al "aceptar que la mujer es un objeto", se empieza a delinear una de las primeras formas de restarle humanidad a las mujeres y por lo tanto convertirlas en blanco de la violencia masculina. En efecto, los estereotipos de género desfavorables resultan, con insistencia, reforzados a través de los medios de comunicación. Por lo tanto, debe importarnos la presencia constante de los medios en la vida de niños y adolescentes, más aún si consideramos que la influencia mediática es sutil, acumulativa y ocurre durante largos periodos de tiempo. En este sentido, algunos científicos sociales advierten sobre varias problemáticas coligadas a la exposición permanente de niños y jóvenes a las plataformas visuales, sonoras y audiovisuales de los medios (Strasburger, 2004).

El interés por analizar la calidad de los contenidos de la publicidad, el cine, la televisión, la radio, la música e internet, tiene que ver justamente con asumir a los medios de comunicación como reales agentes de aprendizaje social con la facultad de influir en los procesos de construcción de identidades de ciertas poblaciones vulnerables y manipulables, como las infantiles y juveniles (Strasburger, Jordan, y Donnerstein, 2010; Strasburger, 2006; Strasburger, 2005; Strasburger y Donnerstein, 1999).

Dicho en otros términos, muchos de los trabajos aquí reseñados le otorgan a los medios de comunicación un papel tan significativo en la educación de la juventud como el cumplido por las demás instancias socializadoras; tal es el caso de la escuela, los pares (o grupos de iguales) y la familia. En coherencia con esto, la construcción de las identidades de niños y niñas estaría sucediendo en un ambiente sociocultural con una alta co-participación o modelaje de los medios (Bandura, 1986). ¿Qué nos dicen las re- 
presentaciones mediáticas de la mujer? Es un aspecto que se abordará a lo largo de este trabajo.

\section{Analizando el contenido de la televisión}

En paralelo al auge de ciertos productos de los mass media (como el boom del videoclip musical en los años ochenta), algunas condensaciones de autores han agrupado los más relevantes análisis de contenido y estudios de los efectos de los medios de comunicación, dejando al descubierto la naturaleza y prevalencia del contenido sexual de los medios, con sus múltiples alusiones sexistas y representaciones que cosifican a la mujer (es decir, la sexualizan), presentándola como un objeto para el consumo y el deleite.

La experiencia de Ward $(2003)^{12}$, nos brinda los resultados de un buen cuerpo de investigaciones (64 análisis de contenido y 36 estudios de los efectos realizados entre la década de los 70s y 90 s sobre medios de entretenimientos en los EE.UU.) que se preguntan por los medios como socializadores de la sexualidad en los jóvenes. Aunque no abordan la pregunta por la mujer exclusivamente, en un $78 \%$ de los estudios a la televisión, el acoso sexual en contra de la mujer se centralizó en el recurso de usar términos denigrantes hacia el género femenino o en la sexualización de sus cuerpos.

Las investigaciones reportaron un enfoque en cámara (en plano visual) hacia los órganos sexuales femeninos, el uso de una amplia variedad de palabras peyorativas para describir a la mujer (por ejemplo, gorda, bimbo, chica idiota, zorra, nena, rubia...) o el uso de la lengua y la mirada de reojo hacia mujeres y niñas. Sumado a lo anterior, los medios estadounidenses promovieron nociones de la sexualidad aligerada y trivial, desatendiendo mensajes preventivos acerca de las consecuencias de una vida sexual sin responsabilidades.

Por otro lado, existen estudios que dan cuenta de la sub representación de la mujer en los medios de comunicación, es decir advierten sobre su menor visibilidad en comparación con el protagonismo del que gozan

12 Esta compilación no incluyó estudios sin componente visual, por lo tanto, no reporta informes dedicados a las letras de canciones, ni a libros o textos noticiosos, así como tampoco aludió a estudios que examinaran el impacto de la pornografía o la exposición a violencia. 
los hombres. Los hallazgos de la investigación de Signorielli, McLeod, y Healy (1994) revelaron que los personajes femeninos aparecieron con menos frecuencia que los masculinos en comerciales publicitarios del canal de música MTV. Sin embargo, cuando la mujer como personaje aparecía, lo hacía con el objetivo principal de "quedar bien" y ser objeto de la atención visual de los demás.

Ello explica su atractivo físico, el uso de ropa sexy, la promoción de productos casi por completo dirigidos al buen aspecto físico y demás indicadores de la perpetuación de los estereotipos habituales sobre las mujeres en la publicidad televisada. Los personajes hombres en contraste, eran mucho más propensos que las mujeres a manejar o controlar el objeto del anuncio publicitario. Lo cual sugiere una tendencia por parte de los anunciantes a que el género masculino pueda asociarse con los puntos fuertes de un producto en particular. De hecho, las clases de productos más a menudo orientados hacia los hombres fueron los de entretenimiento, aventura, poder, acción o control, y no tanto los relativos a la belleza exterior.

De acuerdo con López y Bernad (2007) "las imágenes que se difunden de la mujer a través de los medios, suelen ser negativas, estereotipadas, inexactas y violentas, describiéndolas principalmente por su apariencia y no tanto por sus capacidades" (p. 214). Dicho tratamiento no es exclusivo de la publicidad, pues las investigaciones continúan demostrando que lo indicado en la compilación de Ward (2003) se replica en las pantallas de televisión y en el séptimo Arte.

Entre tanto en la televisión, los resultados de un estudio más actual en el que se observaron 49 episodios de 40 diferentes programas en EE.UU. del año 2011, para examinar las diferencias de género en los programas dirigidos a la audiencia 'Tween' (o pre adolescente) muestran que las mujeres en comparación con la población de EE. UU. Tampoco son lo suficientemente representadas en los programas de acción-aventura (Gerding y Signorielli, 2014).

Aunque los varones superaron a las mujeres, aún en estos programas, es alentador que los espectadores de programas de la escena adolescente puedan percibir un mundo donde mujeres y hombres cumplen con muchas 
de las mismas funciones y tienen más probabilidades de verse en diferentes roles, acercándose a lo que refleja la paridad en la población de los EE.UU. Hubo menos conductas estereotipadas de género en estos programas de lo previsto, pues hombres y mujeres eran retratados con rasgos de personalidad similares, a su vez aparecieron con la misma participación en actividades de comunicación y comportamientos.

Sin embargo, un hallazgo crítico fue que las mujeres todavía se presentan como más atractivas y preocupadas por su apariencia que los hombres. De hecho, en el género de escena adolescente no había mujeres con rostros poco atractivos, pero los hombres se observaron con diferentes niveles de atractivo e incluso careciendo de atractivo. El mensaje es claro: las mujeres pueden participar en todo lo que los hombres pueden, pero al hacerlo deben ser atractivas y deben trabajar para mantener este atractivo (Gerding y Signorielli, 2014).

Según la investigación, a pesar de lo entretenidos que son estos programas, los espectadores están en riesgo de desarrollar concepciones sesgadas sobre los roles de género. Los programas de alfabetización mediática serían una solución ideal y realista para ayudar mitigar algunos de los efectos potencialmente perjudiciales de estos programas. En el escenario español, Guarinos (2011) plantea que:

La inseguridad sobre la propia imagen y el anhelo de ser bello constituyen un tema esencial dentro de las series protagonizadas por personajes en edad adolescente, reflejos de una obsesión generalizada. Sobre todo en el caso femenino, ha sido tradicional considerar la juventud como condición necesaria de la hermosura, contagiando a esta su carácter efímero. La invisibilidad de problemas de salud (alimentarios) relacionados con el físico hace que parezca que no existen dichas enfermedades... (p. 41).

Sumado a los sesgos y discriminación por género donde la mujer es retratada en principio por su aspecto, emerge el componente racial. Otro trabajo sobre 10 muestras (de una semana) extraídas entre el otoño de 1997 y el otoño de 2006 de la difusión prime-time de la televisión norteamericana encontró que los personajes principales en éstos programas aparecen de forma diferente según su color de piel (Signorielli, 2009). 
En particular, la mayor segregación fue para las mujeres negras pues en los programas de las minorías raciales, 6 de cada 10 mujeres negras no se ven trabajar fuera del hogar, son ancladas a la domesticidad o al servicio de otros. Es decir, los roles de prestigio fueron asignados predominantemente a los hombres blancos, y en general no a las minorías étnicas, mucho menos a las mujeres de color, reflejándose discriminación por motivo género y un racismo solapado (Signorielli, 2009).

Valdría la pena inspeccionar, si el sesgo racial de la televisión estadounidense asociado a la discriminación laboral de género, en los términos aquí revisados, también es un parámetro evidente de manera análoga en las pantallas televisivas de otros contextos (europeos y latinoamericanos). Adicionalmente, es preciso mencionar que la mayor parte de los materiales de investigación aquí disponibles procede de los Estados Unidos de América donde la televisión ha conquistado una poderosa posición como el medio primordial de entretenimiento familiar.

\section{Radio e Industria musical}

Más cerca del panorama de la radio de entretenimiento, se realizó un análisis de contenido de 865 comerciales de las revistas 'Radio and Records' y 'Billboard' (enero de 2002 a diciembre de 2003). Ambas revistas buscan influenciar la audiencia tanto de la radio como de la industria disquera y sus principales consumidores son directores de programas de radio, quienes figuran como una especie de 'vigilantes' o 'porteros' de la industria musical (Tanner, et al., 2006).

La primera conclusión de este estudio es que las mujeres mostradas en los comerciales de las revistas son más sensuales y provocativas que los artistas hombres. El hallazgo más importante evidenció que los directores de programas de radio consienten en mostrar a la artista mujer, mucho más que al artista hombre, como un objeto sexual. Incluso, la mujer afroamericana es mostrada como 'hipersexual'. De acuerdo con Tanner et al., (2006) es preocupante ver cómo los estereotipos de belleza y sexualidad están siendo degradados y solamente utilizan el sexo como una representación de una realidad fuera de contexto. Tanto los artistas, como los promotores, como la industria musical en sí, solo están dando a conocer una dimensión (netamente sexual) de la imagen de los artistas. 
Estos resultados se pueden matizar con las aportaciones de Donze (2011), quien después de recoger información descriptiva sobre una muestra de Artistas musicales altamente promovidos en estaciones de radio (417 mujeres y 1.943 Artistas masculinos de música popular) los cuales fueron monitoreados en un periodo de 18 meses a través de un 'análisis de clase latente', encontró que hay (frente a 10 clases de Artistas masculinos) 6 clases de Artistas mujeres: mujeres fatales, modelos de feminidad, princesas del pop, cantautoras chanteuse, feministas underground y otras.

Mirando a través de las clases, fue claro que la raza, la sexualización y el género son aspectos importantes de la definición de los artistas. Por ejemplo, una mayor proporción de las mujeres fueron etiquetadas como atractivas en comparación con los hombres, y más propensas a ser descritas como divertidas, tranquilas, agradables y suaves, brillantes o agridulces. Los hombres, por otro lado, fueron más propensos a ser descritos como activos, agresivos, enojados, callejeros, inteligentes y asesinos; reforzando en ellos actitudes estereotípicas de género.

En este estudio, se revela nuevamente la repetida sexualización de la Artista mujer, pero se explicita que el estereotipo de la 'mujer fatal' (que también es denominada 'femme fatale') es una clase única en lo respectivo a este punto, porque su sexualidad se representa con ciertas variaciones: son objetivadas sexualmente (altamente sexualizadas), pero, al mismo tiempo, desafían esa misma objetivación. $\mathrm{O}$ en otras palabras, invitan al acoplamiento heterosexual mientras, por otra parte, cantan canciones que se rebelan contra éste.

A grandes rasgos, una exploración de la mujer representada en los medios de comunicación nos sugiere que persisten estereotipos discriminatorios, hay una marcada alusión a la sexualidad femenina y una obsesión por la belleza y la juventud. Estas tendencias se replican en los medios de diferentes países por la misma naturaleza de los contenidos de los medios, los cuales están pensados para el consumo masivo.

\section{Análisis de contenido a videos musicales de MTV}

El video musical, empezó a ser un objetivo académico en EE.UU. de forma paralela a su nacimiento y difusión a través del canal de música 
MTV a principios de la década del 80. El videoclip de esta época, era un híbrido contemporáneo de la música rock y las imágenes del cine. En el estudio de Baxter et al., (1985) fue analizada una muestra de 62 videos musicales de MTV, en 23 categorías de contenido. La estructura física de los videos musicales estudiados revela que los productores dependían en gran medida de las técnicas especiales de la cámara, las imágenes de cine y efectos especiales en la creación de videos musicales que cautivaran a la audiencia juvenil.

Los resultados del estudio indican que sobre todo la conducta sexual ya era retratada con frecuencia de modo sugestivo. Asimismo la danza, la violencia y la delincuencia eran mostradas de forma atractiva. Luego Caplan (1985) plantea que la programación de los videos musicales, especialmente del rock, está dominada por muchos actos de violencia y el nivel de violencia en general de los videos musicales es muy alto en comparación con la televisión convencional, pues se evidenció casi el doble de actos de violencia en los videos musicales frente a la televisión comercial. No se encontró, sin embargo, un patrón de diferenciación de género sobre si los hombres o mujeres eran mayores víctimas de violencia. En contraste con la televisión convencional, donde la mujer sí era representada en mayor número de ocasiones como víctima.

Más adelante, Seidman (1992) investigó los estereotipos creados sobre los roles sexuales, ocupacionales y comportamientos representados por los personajes de una muestra aleatoria de 182 videos musicales de MTV. Los personajes masculinos vistos en este análisis eran más aventureros, dominantes, agresivos y violentos que los personajes femeninos, quienes aparecían siendo más cariñosas, dependientes, temerosas, atractivas y sugerentes. Concretamente, en los 182 videos analizados, 37\% de las mujeres llevaba ropa reveladora en comparación con el 4,2\% de los hombres.

Se concluía entonces que los medios de comunicación eran en parte responsables de los auto-conceptos negativos hallados entre las jóvenes mujeres, en correspondencia con las discrepancias descubiertas en los retratos de género. Si bien nadie alegaría que MTV es responsable de la condición de segunda clase de la mujer, éstos indicios sugieren que han sido una fuerza en la continuación de estereotipos que existen sobre cómo las mujeres deben pensar, actuar y trabajar (Seidman, 1992). 
Los estudios sobre otra muestra de 40 videos musicales de MTV analizados a través de categorías, basadas en los roles de género, dieron cuenta de que los hombres aparecieron casi dos veces más que las mujeres en estos videos; pero además ellos mostraron un comportamiento significativamente más agresivo y dominante; mientras las mujeres participaron de una forma significativa en el comportamiento sexual y servil; y fueron frecuentemente objeto de avances sexuales explícitos, implícitos y agresivos (Sommers-Flanagan et al., 1993).

Entre tanto, en los 100 videos de MTV más populares de principios de 1990 los hombres superaron a las mujeres en papeles principales en un margen de 5 a 1 . De los 100 papeles principales que aparecieron en los clips, 80 (80\%) fueron ocupados por grupos de hombres o cantantes masculinos, mientras que 17 (17\%) fueron ocupados por grupos femeninos o cantantes. Además de aparecer con menor frecuencia que los hombres en los papeles principales, las mujeres se mostraron en un rango más estrecho de estos roles (como bailarinas o acompañantes) y además sobresalieron por su apariencia física (Gow, 1996).

Por su parte, los resultados de Tapper, et. al. (1994) indican que los elementos visuales de los videos varían dramáticamente entre géneros musicales. En consecuencia, advertían la importancia de comprender que no es apropiado hablar de éstos como si fueran homogéneos, en razón de que probablemente no todos los tipos de música puedan tener el mismo efecto en los espectadores. Este trabajo señalaba que eran más elevadas las apelaciones sexuales en los videoclips de música rap.

Así que, cuando Wilson (2000) optó por observar géneros musicales tradicionales de la cultura norteamericana, como el country, a pesar de lo que en principio se hubiera esperado, su estudio dio cuenta de la paridad del protagonismo de hombres y mujeres en sus representaciones, diferenciándose este hallazgo frente a las similitudes encontradas tras analizar los videos musicales del rock, hip hop y rap. De acuerdo con la evidencia, las mujeres de los videos musicales de la estación de cable Country Music Television (CTM) son consumidoras, productoras y factor de cambio en los roles tradicionales asociados a ellas en el imaginario colectivo (Bohórquez, 2008). 
Hay que aclarar que una década después, McClane-Bunn (2010), en un análisis más actual y completo a los videos de música country (en efecto hizo un muestreo de los videos musicales de country de la década de los 90 y la primera década del siglo XXI), concluyó que el grado en que las mujeres fueron objetivadas sexualmente resultó mucho más flagrante en los vídeos recientes. Los hallazgos apuntan a un aumento de la mercantilización de las mujeres con el objetivo de atraer más la atención, por lo tanto obtener más dinero, aumentar las ventas de álbumes, conciertos y boletos:

Cuando las mujeres se convierten en simples mercancías, sirviendo solo para complacer el entretenimiento masculino y al espectador masculino, el mensaje que está siendo comunicado a innumerables mujeres en la sociedad es, en palabras de Kilbourne (2000), "el más deshumanizante que puede haber para alguien” (p. 19) [Traducción propia].

Lo anterior coincide con las críticas de Jhally (2007) quien se inclina por la idea de que, independientemente del género musical e incluso aun cuando las imágenes no reflejen el mensaje de la letra de las canciones, en la gran mayoría de videos musicales (transmitidos por el canal MTV) el cuerpo de las mujeres servirá para contar las historias porque la estructura básica del videoclip musical contempla en su narrativa elementos de la fantasía masculina, también denominada "imaginación pornográfica".

El autor advierte: la mujer es mostrada a través del lente de la cámara de video en partes fragmentadas, no como un ser humano integral y completo. Al presentarla así, se cosifica, se le resta humanidad, y aunque imágenes incorpóreas y fragmentadas de las mujeres no pueden causar directamente asalto sexual y violento contra ellas, si contribuyen al mantenimiento de un ambiente sociocultural donde los ataques contra la mujer en el plano real no son asumidos seriamente (Arias-Mendoza y Arroyave (2017); "cultivan las actitudes y valores que legitiman y justifican las agresiones como sí fueran merecidas y provocadas por las mujeres" (Jhally, 2007).

El estudio de Emerson (2002) lo ilustra muy bien, cuando señala el caso de un video del Artista Bobby Brown al lado de la fallecida y reconocida cantante Whitney Houston. A los espectadores del video de la canción "I've Got This Feeling" solo se les permite atisbos de la boca y las piernas de 
la cantante, de sus brazos acariciando el hombro de Bobby y de su cabello. La implicación es que el público no sepa quién es ella (aunque lo sospeche), hasta que el plano se ensancha para revelar su totalidad, mientras ella ríe conspirando con Brown. Emerson (2002) afirma "cortar en trozos visuales a Whitney socava su poder" (p. 122).

¿Es entonces este recurso de la narración audiovisual una forma de legitimar la dominación del hombre sobre la mujer mediante la recreación del ensueño o fantasía masculina de la que habla Jhally (2007)? ¿Se refleja en los videos musicales una relación de poder desigual, con implicaciones sobre los significados que de hombre y mujer podría estar construyendo la audiencia expuesta de modo frecuente a estas visualizaciones? Ya lo declaraba, Smith (2005): "MTV está lleno de contenido sexual, uso de sustancias y violencia ocasional (p. 95)”. Y lo problemático de tal emisión, considerando la ubicuidad de los videos musicales, es que la tendencia por los estereotipos y la objetivación sexual de la mujer ocurre sin restricciones, ni mayores controles, frente a niños y adolescentes en pleno desarrollo de sus identidades.

Precisamente, a la luz de la Teoría de la objetivación y la agencia sexual se desarrolló un sistema de codificación para medir la objetivación sexual y sus correlatos en los videos musicales. Este análisis comparativo pretendió medir la objetivación sexual alrededor de los Artistas, tomando las variables de sexo (femenino y masculino) y de estilo musical ( $\mathrm{RyB}=$ hip-hop, pop y country) (Aubrey y Frisby, 2011).

El marco teórico se basó en los planteamientos de Frederickson y Roberts, (1997) quienes proponen que la objetivación sexual de las mujeres a través de los medios de comunicación les enseña a interiorizar la "perspectiva de los forasteros" de tal manera que llegan a verse a sí mismas como objetos para ser evaluados por otros, una tendencia llamada 'auto-objetivación' (APA, 2007). No obstante, se ha podido comprobar que las mujeres que se ven a sí mismas como un objeto, generan sentimientos negativos hacia sus cuerpos y suelen presentar problemas de salud mental, como la depresión y los trastornos de alimentación (Aubrey y Frisby, 2011). Para Frederickson y Roberts (1997) está claro que los medios de comunicación contribuyen a la cultura de la cosificación sexual: 
Esta cosificación u objetivación sexual se produce siempre que el cuerpo de una persona, o partes del cuerpo, o las funciones sexuales, se separan de la persona, viéndose reducida a la condición de mero instrumento -o sea reducida al cuerpo, a sus partes, o a ese rasgo sexual- como si su cuerpo o sus órganos corporales, (o su sexualidad) fueran capaces de representar totalmente a la persona (p. 175).

De acuerdo con la teoría de la objetivación, los videos musicales contemporáneos sirven para reforzar la noción cultural de que las mujeres se valoran ante todo por sus cuerpos y apariencia. Una conclusión semejante arrojó el trabajo de Wallis (2011) quien, dentro del marco conceptual de la Pantalla de Género de Goffman (1976), perfeccionó y amplió sus principios esenciales como base para el análisis de 12 pantallas no verbales relacionadas con la subordinación, la dominación, la sexualidad y la agresión en los videos musicales, observando un número igual de Artistas principales masculinos y femeninos. Para esta investigación fueron tomados 34 videos musicales de las estaciones de cable MTV y MTV2. Los videos musicales fueron divididos en segmentos de 30 segundos, resultando 253 unidades que fueron codificadas alrededor de 'la exhibición de género'. Los resultados revelaron que muestras significativas de género refuerzan principalmente las nociones estereotipadas de las mujeres como objetos sexuales.

Por su parte, el análisis sobre una muestra que incluye otros canales de televisión además del controvertido MTV (dos estudios en uno: 120 vídeos grabados de MTV, MTV2, VH-1, BET y CMT; y 20 videos del programa de tarde-noche de BET) corrobora que la raza sí es un factor importante cuando se examinan los roles de género en videos de música (Turner, 2011). De modo que si la mujer es un objeto sexual para el consumo, la mujer afroamericana resulta ser, en mayor proporción, presa del encasillamiento "hipersexual". Habría que decir, el cuerpo de la mujer negra históricamente ha sido explotado como si se tratara de una mercancía (Balaji, 2010; Tyree, 2009; Adams y Fuller, 2006).

Lo paradójico es que cánones de belleza eurocéntricos, o si se quiere los parámetros de atractivo físico femenino que se imponen en la mujer blanca, son replicados en los videos protagonizados por mujeres de color. Hay evidencias de que la visión de la mujer negra es plana con respecto a la 
variedad de mujeres afroamericanas que existen en la población de EE.UU. con cuerpos robustos y no tan delgadas (Emerson, 2002).

Ciertas investigaciones señalan que al glorificar el estándar de belleza blanca, con la propagación de las características eurocéntricas en los personajes de los videos musicales (delgadez, narices afiladas, cabello liso rubio y abundante...) se podría estar generando un efecto negativo sobre el autoestima de las espectadoras negras; quienes además no están siendo representadas de una manera realista, en cambio sí opresiva y discriminatoria, pues en la medida que la corporalidad de la mujer afroamericana y su identidad cultural aparecen sojuzgadas a parámetros estéticos que no logran contener su diversidad, o en la medida que es reducida a objeto sexual y acompañante de estrellas del rap, en posiciones de subordinación frente a sus homólogos masculinos — como si no pudiera ser retratada de otra forma- es segregada (Conrad et al., 2009; Zhang et al., 2010).

Hasta este apartado la gran mayoría de estudios claramente nos sugieren que los contenidos de los videos musicales menoscaban la imagen de la mujer, la presentan altamente sexualizada, objetualizada, obsesionada con el atractivo físico. Los videos musicales nos dicen que la mujer es objeto de consumo, de mirada, que es heterosexual, está ahí para el hombre y por un hombre, apenas sí se refieren a otras preferencias sexuales posibles como el lesbianismo (Emerson, 2002); se invisibiliza su maternidad, que antes era un indicador recurrente de feminidad y se resalta su belleza corporal, su juventud, su sexualidad.

En síntesis, la mujer es discriminada por su género, porque en casi todos los estudios que midieron su representación no hay paridad (el hombre generalmente superó la frecuencia de aparición con respecto a la mujer aunque ahora menos que en el pasado), ni ostenta roles de prestigio, ni siquiera cuando es intérprete o solista porque vuelve a ser objeto sexual, aun cuando observamos que ciertas cantantes han alcanzado poder y estatus dentro de la industria musical, en mayor proporción continúan recurriendo a mostrarse muy sexuales o se acompañan en los videos de mujeres dispuestas como objetos sexuales (Balaji, 2010).

Un rasgo acentuado en el contexto de EE.UU., es que la mujer afroamericana es discriminada por su raza, persiste atrapada en los estereotipos 
relativos al sexo (Railton y Watson, 2005) y en la gran mayoría de estas investigaciones las metodologías dan cuenta de esto. Ahora bien, ya que el mayor despliegue, en los análisis de contenido a los productos de la industria musical, se centra en el video, valdría la pena preguntarse... ¿Qué dicen las letras tras esos videos musicales? Finalmente, la canción de consumo también se escucha a través de la radio e internet, y aunque el video musical sea visto e impacte a la audiencia con fuerza, las personas reconocen, aprenden y repiten las letras de las canciones.

Teniendo en cuenta que varios de los estudios diseñaron sistemas de observación dirigidos a caracterizar y medir el lenguaje audiovisual expuesto en las pantallas de televisión (es decir se detuvieron en los grados de desnudez según el sexo de los Artistas, en el nivel de atractivo de los personajes, en el enfoque de la cámara de video sobre los órganos sexuales, en el tipo de temáticas de las historias recreadas o escenificadas, en el número de elementos masculinos y femeninos en aparición...) ¿cómo se adaptarían tales indicadores para rastrear en las letras de las canciones, por ejemplo, la estereotipación de género o la cosificación sexual de la mujer? ¿La letra e imagen corresponderían de modo coherente en sus significados, intenciones y mensajes, complementándose o contrariándose? En el siguiente segmento, algunas investigaciones examinaron letras y videos musicales, dando algunas luces sobre estos cuestionamientos.

\section{Estudios conjuntos: Letras y videos musicales}

En Chaney (2009), es analizada la canción del género musical RyB "Trapped in the Closet", del Artista R. Kelly, una de las piezas singulares, integrales y comercialmente exitosas de la industria del hip-hop surgida en los últimos años. El propósito de esta investigación se concentró en examinar el lenguaje de la intimidad y el compromiso usado por hombres y mujeres afroamericanas en los capítulos 1 a 5 de la canción de R. Kelly, ya que su producción en realidad es una especie de serie audiovisual con 22 capítulos (como si fueran 22 episodios de una misma historia cantada).

Específicamente, los patrones de lenguaje relacionados con la intimidad estaban vinculados con el amor, la excitación sexual, la satisfacción sexual, las percepciones aceptables y el comportamiento sexual inaceptable. 
De otro lado, los patrones de lenguaje en relación con el compromiso se basaron en palabras indicativas de compromiso matrimonial (por ejemplo, el marido, la esposa, etc.), el nivel de la devoción que las parejas tienen el uno al otro, el deseo de trabajar en la relación y un interés en mantener la relación fuerte.

Las mujeres negras fueron retratadas tanto en la letra de la canción como en la puesta en escena de los capítulos, participando del engaño sexual, o infidelidad conyugal, así también el hombre afroamericano aparece siendo infiel, lo cual sugeriría que es una actividad con igualdad de oportunidades de ser realizada por ambos géneros. No obstante, este análisis no profundizó en medir o caracterizar las discrepancias de los géneros y se concentró en la relación afectiva.

Por su parte, Click y Kramer (2007) examinaron dos canciones populares y sus videos, "100 Years" y “This One's for the Girls". Las dos canciones resonaron con su público objetivo a lo largo de 2004, terminando el año como las canciones número tres y número nueve, respectivamente, en las listas de la revista 'Radio and Records' del género musical contemporáneo para adultos.

Con este trabajo, se analizaron las letras y los videos de estas dos canciones para determinar las imágenes de hombres y mujeres, con el propósito de atender un tipo de música que no había despertado el interés académico (en comparación con el rap o el hip hop). La razón por la cual fueron elegidas juntas, fue que ambas canciones y sus videos proporcionaron una oportunidad única para examinar las ideologías presentes en los textos de la cultura popular de todos los días y las formas en las cuales trabajan para establecer y mantener relaciones de poder desiguales.

En efecto se hallaron diferencias significativas, por ejemplo en lo respectivo a la presentación del desarrollo humano individual en mujeres y en hombres. "This One's for the Girls" es una canción festiva y optimista, mientras "100 Years" es contemplativa y suave; en la primera se presenta una imagen de la mujer como que nunca cambia, no crece o madura, como si no se reconociera un proceso de maduración en ella, ni siquiera en la letra pues se observa el reiterado llamado de mujeres, de todas las edades, como 
si fueran niñas o 'chicas', mientras que en el video si retrata a mujeres de diferentes edades.

En la segunda canción, se ilustra en cambio la imagen de un hombre creciendo en madurez a lo largo de su vida, asumiendo responsabilidades, convirtiéndose en sabio, y esforzándose por más, incluso cuando alcanza los 99 años, tanto en el video como en la letra. La conclusión tras contrastar estas dos piezas de un mismo género musical (escuchado mucho más por un público femenino) es que por desgracia los mensajes en esta clase de música tampoco proporcionan a las mujeres una gama de opciones que les permitan empoderarse y asumir nuevos roles o nuevas imágenes de género (Click y Kramer, 2007). Otras investigaciones hallaron contradicciones importantes cuando se analizaron la letra y el video musical conjuntamente (Horn Sheeler, 2007):

La exitosa y muy popular canción "Stupid Girls" de la cantante estadounidense 'Pink', cuando fue examinada cuidadosamente develó que alienta a las mujeres a negar a la poco profunda 'estúpida chica', invitando a las jóvenes a que no sean tontas y superficiales, lo cual parece positivo en primera instancia. Sin embargo, los mensajes representan, al mismo tiempo, una ideología de la dominación masculina que en el camino retrata positivamente a los varones. Posiciona a las mujeres alrededor de la experiencia masculina y no se le atribuye a los hombres responsabilidad por la existencia de las mujeres tontas y superficiales; tampoco ofrece la canción un abanico de opciones de mujer (p. 15-16).

Más resultados inquietantes se hallaron al explorar los significados de la 'mujer independiente' en las letras y videos de artistas masculinos y femeninos del rap. Los hallazgos dieron cuenta de que raperos y raperas utilizan términos misóginos para alabar a la mujer independiente y yuxtaponen imágenes de independencia con la riqueza material (Moody, 2011): "las raperas al usar estas palabras misóginas implican que las aprueban, esto soporta la Teoría del Grupo Enmudecido, demostrando que sus ideas sobre las mujeres son omitidas y solamente articulan la perspectiva masculina" (p.50). A menudo, discuten el sexo como la principal herramienta para la obtención de la independencia y presentan una lucha de poder en la que las mujeres tratan de ganar la mano. 
Sorprendentemente, su representación de independencia no se centra en las mujeres que toman una decisión consciente para ser independientes y mejorar su vida familiar. En su lugar, la independencia se presenta como un medio para comprar bienes materiales y controlar a los hombres. Es una independencia acorde con la forma como los hombres la entienden para sí mismos, y la han proyectado durante largo tiempo, pero ahora las mujeres la adoptan también (Moody, 2011).

Es importante poner el concepto de independencia en el contexto apropiado, pues las mujeres que se exponen a estas concepciones y definiciones, deben tener claro que la independencia, tal y como se describe en algunas canciones del rap, no es irremediablemente el único ideal para las mujeres, ni la única manera de entender su emancipación (Moody, 2011):

Sus representaciones de las mujeres independientes son idealistas, y esas mujeres son extraordinarias y escasas, pero no siempre independientes. Aunque no parezca tan glamoroso, las letras de las canciones también podrían destacar a los hombres y mujeres que trabajan duramente por balancear su vida en familia con sus carreras profesionales (p.54). [Traducción del autor]

Por su parte, en el escenario académico de la Universidad de Sevilla (España) se llega a conclusiones parecidas luego de analizar la representación femenina en canciones de éxito internacional (un corpus de trabajo de 30 canciones, con sus respectivos videoclips musicales, correspondientes a los diez top ten de verano entre 2009 y 2011), pues se advierte allí un perfil de mujer cada vez más cercano al perfil del hombre. La mujer es ahora protagonista de sus temas y videos, pero usa a otras mujeres como decoración de sus soportes visuales, tal como lo hacen los cantantes masculinos. En este aspecto, quizás la diferencia más notable entre hombres y mujeres radique en que las mujeres se proponen como objeto ellas mismas, desde su propia voluntad y control, como protagonistas, son también sujetos de acción y no objetos pasivos (Guarinos, 2012).

Los dos estudios coinciden en que el poder, control e independencia de la mujer se expresa en términos de su potencia sexual y capacidad de sometimiento hacia los hombres desde la perspectiva sexual (Moody, 2011). 
Por ende, si en sus perfiles se proponen como objetos sexuales las mismas mujeres, aun cuando su intención sea denotar poder, en los términos de Frederickson y Roberts (1997) se auto-cosifican, con lo cual, desde la letra y la recreación audiovisual, se refuerzan propuestas de mujer con escasas implicaciones positivas, o con pocas fórmulas de empoderamiento novedosas (distintas al poder sexual) para otras mujeres. Es un poder, entonces, construido desde una perspectiva masculina.

En síntesis, cuando se hacen análisis de contenido a la letra de canciones en combinación con el video, también se manifiestan reforzamientos de estereotipos de género, distorsión de conceptos, se advierte que letra y video están, de modo deliberado, dispuestos para capturar la atención de la audiencia, y no tanto para crear conciencia o sensibilizar sobre los problemas que afronta la sociedad.

De hecho, al llevar a cabo deconstrucciones detalladas, se develan mensajes superpuestos e ideas sutilmente insertadas, que no se perciben con solo oír las letras de las canciones de modo desprevenido y casual. A su vez, en la fascinación del video musical que atrapa y seduce, muchas veces tampoco se logran advertir en una primera mirada los simbolismos, movimientos, maniobras técnicas y mucho menos lo expresado en las letras sobre la mujer.

\section{E1 caso especial del Rap: Contribuciones a la misoginia}

La misoginia, básicamente, es el odio o el desprecio hacia las mujeres, instituido como ideología. De acuerdo con Adams y Fuller (2006) las ideas misóginas expresadas en la música no son un único o nuevo fenómeno, por lo tanto, la misoginia en sus variadas formas no existe en el vacío sino que es una parte de un macro sistema social, cultural y económico, que sostiene y perpetúa la ideología; "un sistema que es patriarcal (...) en el sentido de la dominación y el imperio de los hombres. Este sistema fue el modelo utilizado para el desarrollo económico, político y la estructuración social de Estados Unidos" (p. 492).

En el contexto norteamericano existe, en consecuencia, una fuerte inclinación entre los académicos por analizar letras de canciones del hip-hop/ 
rap, pues éstos dos géneros musicales (y con énfasis el rap) evidencian un pronunciado contenido misógino que ultraja a las mujeres (especialmente a la mujer afrodescendiente). El origen de esta música data de los años 70 entre la población negra de los EE.UU. residente en las ciudades. En sus albores, se convirtió en un vehículo de expresión de la estética juvenil urbana, mediante la cual eran relatadas experiencias y vivencias cotidianas marcadas por problemáticas asociadas a la marginación, la pobreza, prostitución y el tráfico de drogas (Krohn y Suazo, 1995).

Desde la composición e interpretación de canciones de rap, los Artistas se convirtieron en voceros de la comunidad afrodescendiente, oprimida e impactada a través de los años por la segregación racial y de clase, topándose con la aceptación de su mismo grupo y posteriormente de un extenso público, lo cual se tradujo en el incuestionable éxito comercial del rap, al que más tarde la industria discográfica convertiría en un lucrativo negocio.

Adams y Fuller (2006) examinan el uso de la ideología misógina en el 'rap gangsta' (un subgénero del rap) trazando la conexión entre la prevalencia de la misoginia en el rap y la forma negativa como la imagen de la mujer afrodescendiente ha sido históricamente caracterizada y propagada, a través de prácticas culturales instauradas por el sistema patriarcal capitalista estadounidense, basado en los principios de supremacía de la raza blanca: elitismo, racismo y sexismo.

El uso de la ideología misógina en el rap sería, según lo anterior, el resultado del racismo generalizado y los dogmas sexistas manipulados a favor del hombre blanco para colonizar las mentes de los afroamericanos y los estadounidenses en general. Ello explicaría que la misoginia haya permeado la totalidad de estamentos sociales, hasta convertirse en una parte de la conciencia de América, acarreando un efecto profundo en la psique interna de la población afrodescendiente (Adams y Fuller, 2006).

De tal manera que si la ideología se alimenta, no solo de odio hacia las mujeres sino también de odio hacia la negritud, la mujer afroamericana se hallaría singularmente situada en el cruce de estas dos aversiones. Desde el comienzo de la institución de la esclavitud, las mujeres afroamericanas han sido entonces el objetivo principal de la propaganda estereotipada y de 
los prejuicios sexuales, de los que se ha servido el sistema patriarcal para justificar y naturalizar los abusos sobre la mujer negra ${ }^{13}$ :

Desde la fundación de los Estados Unidos, los mitos y los estereotipos se crearon para legitimar la opresión racial y sexual de las mujeres afroamericanas. Siendo ambas, negras y femeninas, las mujeres afroamericanas se convirtieron en el último "otro", que permitió que el patriarcado blanco usara esa diferencia como justificación de sus conductas opresivas (p. 943). [Traducción del autor]

En la actualidad a través del rap se estaría experimentando una especie de readaptación de viejas representaciones estereotipadas de la mujer afrodescendiente, por ejemplo con el uso repetido de las palabras denigrantes. Krohn y Suazo (1995) señalan la canción del rapero Dr. Dre “Nuthin' but a 'G' Thang" la cual es catalogada un himno a la misoginia. Pero también mencionan a otras canciones de Artistas como Snoop Doggy ("Doggystyle”), el grupo Niggaz with Attitude N.W.A. (“One Less Bitch”), K7's ("Come Baby Come")... Destacado en ellas el uso repetitivo de la palabra "perra" o "puta" para señalar el orgullo masculino por abusar del poder sexual sobre las mujeres en ciertas situaciones, así como la promoción de la violación sexual grupal sobre las mujeres.

13 Adams y Fuller, (2006) sostienen que los mitos e ideas en torno a la mujer de color propagados en el pasado mediante estereotipos como "the mammy", "the sapphire", "the tragic mulatto", "the matriarch" y "the jezebel" (p. 944) fueron creados para predisponer la cultura americana a la aceptación de la opresión racial y sexual de las mujeres afroamericanas. Estas imágenes se encuentran regularmente (en su versión modernizada) en muchas de las letras misóginas del rap por ejemplo "the bitch", "the ho", o "the swathy" pueden ser considerados equivalentes de etiquetas de mujer que alientan una idea de subvaloración o desprecio por las mujeres negras. De acuerdo con esta visión estereotipada, "the sapphire" o "el zafiro" (en el rap, [sería "la perra"] o "the bitch") era una mujer afroamericana que dominaba a toda su familia incluyendo a su hombre, una mujer socialmente agresiva, llena de actitud que tenía una lengua de fuego y que aplastaba las aspiraciones de su hombre o de los hombres en general. "The jezebel" (referida como el "ho" [o ramera] en el rap) representaba a una mujer sexualmente agresiva, que quiere y acepta la actividad sexual de los hombres en cualquier forma, y que a menudo utiliza el sexo como un medio para conseguir lo que quiere de ellos. Esta imagen en particular de "the jezabel", servía para justificar la violación sexual de las esclavas negras por los patronos blancos. 
Weitzer y Kubrin (2009) explican que la misoginia se puede ver reflejada en la letra de las canciones del rap, pues muchas de estas "glorifican, motivan y aprueban la objetivación sexual, explotación y victimización de las mujeres" (p. 10). Esta investigación profundiza en las temáticas misóginas con su análisis de contenido sobre una muestra representativa de 403 canciones de rap, seleccionadas luego de tomar todos los álbumes de rap, desde 1992 hasta 2000, que alcanzaron el estatus de platino [venta al menos 1 millón de copias; se identificaron $(n=130)$ ] de acuerdo con el listado de la Asociación de la Industria Discográfica de Estados Unidos (RIAA). Los hallazgos dieron cuenta de que la misoginia estuvo presente en el $22 \%$ de las 403 canciones ( $\mathrm{n}=90$ canciones, por 31 raperos). Esto significa que la misoginia puede ser mucho menos típica en la música rap de lo que algunos críticos creen, pero claramente es un tema significativo.

Las raperas representaron solo 5 de las 90 canciones misóginas, así como un adicional de 8 canciones (fuera de los restantes 313 ) que no tenían letras misóginas. La escasez de mujeres Artistas demuestra el dominio masculino durante este período de tiempo, especialmente en el nivel de platino. Pese a que los mensajes misóginos aparecen con menos frecuencia en el rap de lo que comúnmente se había creído, se enfatiza en la importancia de esta problemática, pues no es simplemente una cuestión de la frecuencia con que aparezca. También es importante dimensionar la naturaleza y la intensidad de los mensajes (Weitzer y Kubrin, 2009).

Su análisis de contenido identificó cinco temas misóginos que aparecen con cierta insistencia: (a) nombres peyorativos o palabras degradantes para avergonzar a las mujeres, (b) la objetivación sexual de las mujeres, (c) la desconfianza de las mujeres, (d) la legitimación de la violencia contra la mujer, y (e) la celebración de la prostitución y el proxenetismo (Weitzer y Kubrin, 2009). Este trabajo académico también pretendió develar las formas en que las letras reflejan las relaciones sociales de género, las presiones de la industria discográfica y las condiciones vividas en los vecindarios de las comunidades desfavorecidas o lo que también ha sido llamado el "código de la calle":

Sugerimos que los raperos cuyas canciones retratan negativamente a las mujeres están influenciados principalmente por tres de las fuerzas 
sociales más grandes: las relaciones de género, la industria de la música y las condiciones de la vecindad local. La influencia más difusa es el orden de género más grande, que incluye la valorización cultural de un determinado tipo de masculinidad (p. 5).

Otro de los argumentos más reveladores en esta investigación plantea que la música popular en los últimos tres decenios hace parte de una de las más grandes resistencias culturales al feminismo, un intento de bloquear el progreso hacia la igualdad de género y resucitar la dominación masculina. De esta manera, el rap sería un "mecanismo de reacción a la emancipación de las mujeres, que puede ser visto como parte de un proceso ideológico más amplio para persuadir a la población de que la supremacía masculina heterosexual es natural y normal. Sería el rap uno de los instrumentos contemporáneos que "controlan las imágenes" usadas para subordinar a las mujeres negras, a su vez, las letras sexistas suministrarían justificaciones para participar en actos de violencia contra las mujeres negras (Weitzer y Kubrin, 2009).

Por lo tanto, con las etiquetas peyorativas (por ejemplo, "the bitch" o "la perra”) los raperos estarían tratando de poner en su lugar a aquellas mujeres que muestran ser fuertes e independientes. E incluso, las mujeres que han logrado algún status en ese gremio, se auto reconocen dentro de ese mismo lenguaje misógino dominante de los hombres. Es decir, aun cuando se enfrenten a la opresión con letras - las raperas adoptan posturas de resistencia a la degradación en sus mensajes-, la contradicción sufrida es que la perpetúan auto describiéndose a sí mismas en términos degradantes.

Por ejemplo, la rapera Lil Kim se autodenomina "la reina de las perras". Si bien algunos podrían argumentar que estas palabras no son siempre despectivas (o pretenden ser peyorativas) en el marco de la subcultura del hip hop/rap, la investigación demuestra que, a menudo, son percibidas como ofensivas dentro de la sociedad más amplia. El rap, por otro lado, también puede ser visto como un esfuerzo por controlar a todas las mujeres (Weitzer y Kubrin, 2009), ya que esta música es consumida por una amplia variedad de grupos raciales y étnicos, dentro y fuera de los EE.UU. Cabe resaltar que la transnacionalización y globalización de la canción de consumo masivo conducen a que las letras de estos productos mediáticos, tanto en el género musical urbano (hip-hop/rap, RyB o reggaetón) como en otras expresiones 
musicales (pop, country, folk, rock...) aborden temas universales, pues se está ante una industria que trae consigo una comunicación intercultural.

La pertinencia de esta idea estriba en que, desde la época aristotélica, se sabe que la música no solo influye en nuestro estado de ánimo, sino que también infiere en nuestra capacidad volitiva, es decir puede modificar nuestros comportamientos. "El paso por tanto del estereotipo al prototipo es casi natural" (Guarinos, 2007). Las imágenes degradantes o negativas del rap sobre la mujer, como consecuencia, tendrían efectos reales en la medida en que contribuyen a la socialización del género y a perpetuar la desigualdad de género en toda una comunidad o sociedad determinada.

Si consideramos la capacidad de trascender fronteras e imponerse como referentes para un buen número de jóvenes de otros espacios, habría que reflexionar sobre la propagación de la discriminación intergenérica y la estigmatización de los afrodescendientes. Estos sesgos, fomentados por las compañías discográficas mediante la repetición constante de las canciones en las estaciones de radio y otros medios de comunicación, promueven la mentalidad de que la única manera de ser de un hombre negro o latino, es mostrándose duro o agresivo, denigrando a las mujeres, a los homosexuales, denigrando al otro.

Tal privilegio de la masculinidad (heterosexual) hegemónica y de la negativa representación de las mujeres estaría impulsada, entonces, por un interés en la venta de discos. Sin embargo, habría que cuestionar si toda la música popular evidencia el mismo tipo de mensaje misógino o sexista (crudo, claro y extremo) en contra de la mujer que se palpa en el rap. En este sentido, otro estudio exploratorio - descriptivo realizó un análisis de contenido sobre la frecuencia de aparición de palabras del argot popular, etiquetas, apodos o estereotipos femeninos degradantes que puedan, deliberada o involuntariamente, sugerir una subvaloración de las mujeres en las letras de canciones. El estudio tomó las canciones más populares entre los años 2006 a 2008 que alcanzaron el estatus de platino (venta de al menos 1 millón de copias) para asegurarse de que la música había llegado a un segmento sustancial de la población.

En total fueron 150 canciones clasificadas según los géneros musicales: pop, RyB, hip-hop/rap, alternativo, latino, folk, rock y country. Los datos 
revelaron de nuevo que los Artistas afroamericanos son más propensos a utilizar palabras que se refieren a las mujeres como "perras" y "vagabundas". De los ocho géneros, el hip-hop/rap fue donde mayor número de palabras de la jerga popular se encontraron articulando mensajes referidos a las mujeres como sexualmente permisivas y agresivas. A diferencia del pop, o de la música country, el jazz o el rock, fue en el hip-hop/rap donde primaron el argot y los temas misóginos que comunican roles de género poco realistas. Este hallazgo demuestra el apoyo continuo promovido en las canciones sobre el lugar que tienen los hombres en la sociedad (superior) y el valor dado a las mujeres (inferior). La exposición a estas palabras de argot durante un largo período de tiempo, puede llevarnos a internalizar las etiquetas y medirnos de conformidad con sus significados (Frisby, 2010).

De ahí la necesidad de realizar análisis a los contenidos de la programación musical emitida por la radio, porque los mensajes ofertados en este medio pudieran estar llegando a ser más poderosos de lo que aparentan, desde esa emisión constante de canciones para el consumo de las masas, con letras que nos hablan de formas concretas de ser y comportarse de las mujeres y los hombres (Arias-Mendoza y Arroyave, 2017).

La problemática con las letras del rap en particular, es que emergen de las experiencia de los jóvenes de los barrios más desfavorecidos — la tercera fuerza social detrás del rap misógino- por ende proyectan la descomposición social tangible en la realidad de la calle. El grado en que un género musical, y sobre todo Artistas masculinos dentro de ese género respaldan la supremacía masculina en sus letras, pudiera relacionarse con los obstáculos de los hombres para reafirmar su masculinidad, debido a la falta de acceso a las vías institucionales o convencionales a través de las cuales esta masculinidad podría establecerse (Weitzer y Kubrin, 2009).

Las duras condiciones del 'gueto' o del barrio, proporcionan a los residentes, con pocas fuentes de autoestima, maneras alternativas para ganar respeto y estatus. La violencia es, por lo tanto, un medio para la obtención del respeto de los demás y un método de castigo; a su vez la admiración se consigue por explotar económica y sexualmente a las mujeres, mediante mecanismos "legítimos" de supervivencia como la prostitución (proxenetismo). 
No es casualidad que muchas de las letras del rap inciten a la degradación verbal femenina mientras exaltan al hombre hostil y celebran las figuras del "proxeneta" y del "gangster". Debido a las implicaciones que el sexo tiene para el estado social local y la estima del joven negro, es muy apreciado como un testimonio no de amor sino de control (poder o dominio) sobre otro ser humano. La objetivación sexual se refiere en este escenario a la idea de que las mujeres solamente son buenas para el sexo (Weitzer y Kubrin, 2009). Por ello, en muchas de las letras del rap misógino se exhorta a los hombres a evadir el compromiso, el matrimonio, el sostenimiento familiar o la paternidad responsable. En cambio, la mujer debe ser usada (sexualmente) y luego desechada.

Desde esa lógica, se explica que los raperos hablen en sus letras del prototipo de mujer caza fortunas, interesada y traidora que va tras del dinero de los hombres y para ello se vale de sus encantos; o que sugieran que "todas" las mujeres buscan embarazarse para explotar económicamente a los hombres, por lo cual es conveniente acostarse con ellas pero evitar vincularse emocionalmente y mucho menos comprometerse formalmente. Sumado a lo anterior, se ha discutido la extrema presión que es sentida por los hombres jóvenes afrodescendientes de los barrios más pobres por mantener sexo casual con las mujeres como una forma de afirmar su masculinidad. Esta presión social puede derivar luego en la agresión sexual o violación contra las mujeres (Weitzer y Kubrin, 2009).

Muchos críticos son propensos a atribuirle a la música rap la responsabilidad por el sexismo, la misoginia y los actos de violencia en contra de la mujer, debido en parte a que muchos artistas en sus vidas reales se han visto comprometidos judicialmente en actos de violencia sexual y doméstica (Krohn y Suazo, 1995). Sin embargo, como bien lo señalaban Adams y Fuller (2006) estos problemas no se originaron con la música rap sino que han estado arraigados a la cultura americana y un análisis de este fenómeno debe considerar también el contexto general de las representaciones de los medios de comunicación de la sociedad estadounidense.

Otro matiz, la dicotomía mujer buena-mujer mala, nos lo revela el análisis a 24 canciones alusivas a las madres de crianza de los raperos y a las madres de sus hijos pequeños. De acuerdo con esta investigación, los rape- 
ros masculinos vieron a sus madres como dignas de amor, adoración y respeto, mientras las mamás de sus bebés fueron simples conquistas sexuales retratadas como explotadoras sin valor, no éticas, a quienes etiquetaron de 'putas', 'perras', 'proxenetas' y causantes del "drama" y "estrés" de los hombres (Tyree, 2009).

Se menciona como ejemplo a la canción del rapero Snoop Dogg "I Love My Momma”, donde el artista afirma casi 30 veces que ama a su madre. A su vez, otros raperos expresaron el agradecimiento por el trabajo duro, sacrificio, asesoramiento y apoyo recibido de sus madres. Manifestaron además su pesar por el dolor o la angustia que causaron a sus madres durante su infancia y el orgullo por los trabajos que sus madres padecieron en la crianza de ellos durante los "tiempos difíciles", cuando tuvieron que quedarse solas, sin un esposo que las respaldase. La paradoja es que ahora los raperos masculinos, en sus composiciones, denigran y encuentran, además, justificación al maltrato verbal, físico, psicológico y al abandono al que someten a las madres de sus bebés.

La realidad que parece perpetuar el rap a través de sus letras conduce a realizar más preguntas sobre la sutileza y crudeza de la misoginia, el sexismo y la legitimación de la violencia en contra de las mujeres, pues como sostienen Adams y Fuller (2006) estas problemáticas sociales no atañen de modo aislado, ni se originan exclusivamente en la música rap, y pudieran estar presentándose de forma menos explícita a través de los mensajes construidos en las letras de otros ritmos musicales. En América Latina se advierten, de manera a priori, similitudes entre la semántica del hip hop/ rap y expresiones culturales de incidencia más reciente como el reggateón, el cual surgió como un género comercial híbrido en la Isla de Puerto Rico a finales de la década de 1990 y posteriormente se estableció como baile favorito de los adolescentes dentro de la Isla y en otros países del caribe como República Dominicana y Cuba.

El reggaetón, de hecho, se encuentra estrechamente vinculado con las clases sociales subordinadas de las áreas urbanas del Caribe hispánico y Estados Unidos (San Juan, Santo Domingo, la ciudad de Panamá, Nueva York y Miami). En algunos casos, las letras de las canciones se identifican con la defensa de la negritud y realizan enérgicas críticas a la hegemonía blanca, como ocurre en el rap (Duany, 2010). 
En 2004, el éxito de ventas "La gasolina" del artista Daddy Yankee (cuyo nombre de pila es Ramón Ayala) lo consolidó como una de las formas dominantes de la música urbana en las poblaciones de origen hispano y norteamericano. Sin embargo, "el aspecto más problemático del reggaetón es que contiene una gran dosis de violencia sexual, particularmente dirigida contra las mujeres, quienes, de forma reiterada, reciben apelativos ("mamis", "gatas" o "perras", como se les denomina comúnmente en el género)"(p. 183 y 184).

Aun así, en un contexto en el que la propia familia y la sociedad de la información promueven la discriminación hacia la mujer y la desigualdad de género, el reggaetón y las imágenes femeninas y masculinas que este difunde, son una manifestación que se suma a las diferentes expresiones de la cultura machista, que refuerzan el rol dominante de los hombres (Martínez, 2014).

\section{Coda: Investigaciones en España, México y Colombia}

Algunas investigaciones en España examinan canciones populares, la mayoría transmitidas de manera oral, o en prácticas sociales inherentes a la cultura española, sin alcanzar a ser masificadas a través de medios como la radio (Berrocal y Gutiérrez, 2002; Hidalgo, 2010). Sus hallazgos, entre tanto, son interesantes porque comprueban la prevalencia de la perspectiva masculina tradicional a través de las representaciones de los roles de género. En estas piezas musicales, las mujeres son domésticas: lavanderas, costureras, peinadoras, planchadoras, etc. Mientras los hombres son soldados, caballeros, barqueros o zapateros. En muchas de estas letras, se observa una clara dependencia de la mujer hacia su marido, pues es la figura del esposo quien gana el dinero, mantiene a la mujer y a los hijos. Desde lo analizado en ese tipo de canciones populares, el papel de la mujer no está igualado con el del hombre, estableciéndose claras diferencias entre ambos (Berrocal y Gutiérrez, 2002).

Por su parte, Hidalgo (2010) explica que la música tradicional perpetúa de generación en generación roles que hombres y mujeres deben asumir dependiendo de su sexo. En el relato de las canciones populares, según su análisis, las mujeres están relegadas al mundo de lo privado, lo doméstico y 
familiar, mientras que los hombres dominan el mundo público y el trabajo remunerado fuera del hogar. De otra parte, en la investigación realizada sobre la iconografía y representación de los textos de las canciones de la región andina de Colombia (específicamente de los Departamentos de Boyacá y Cauca) se llega a conclusiones semejantes (Muñoz, 2005).

Se advierten contrastes con respecto a las propuestas de mujer halladas en investigaciones donde las canciones estudiadas son para la distribución y el consumo masivo. Parecería que la música popular es más conservadora y la música comercial es más liberal, por lo tanto, se podría pensar que esta última daría más cabida a modelos innovadores de hombre y mujer. Sin embargo, y según lo relevan los hallazgos, no podemos decir que frente a las canciones tradicionales, las representaciones femeninas de la música comercial moderna mejoren substancialmente la condición sociocultural y el valor de las mujeres en la sociedad en general, ni que se estén en su mayoría promoviendo estereotipos de género igualitarios o simétricos.

En otra investigación Fernández Poncela (2005) recoge y revisa algunas letras de la canción romántica, una muestra de la canción popular, en el México de las últimas décadas hasta nuestros días. De esa selección de letras analiza e interpreta sus mensajes dentro del discurso o narrativa social tradicional hegemónica en el modelo cultural dominante, señalando algunos rasgos de las relaciones intergenéricas, en las cuales la forma en que se presentan las interacciones de hombres y mujeres en el plano afectivo también parecen ser retratadas desde una visión masculina.

Según Fernández Poncela (2005), la temática de la mujer ingrata o infiel se reitera en el marco de la canción romántica —al igual que se reitera en otros tipos de música-, sugiriéndose como uno de los temas preferidos por los autores. También son frecuentes las comparaciones de la mujer con un animal, lo cual facilita o justifica su domesticación, de modo semejante los hombres son comparados con animales pero se hace para otorgarles cualidades positivas como la valentía de un oso o la virilidad de un gallo:

En muchas ocasiones las letras de estas canciones, al compararlas con la realidad social, parecen una especie de "mundo al revés"(...) En el sentido de que en general, y en la práctica común y cotidiana, es el hombre el infiel o el que abandona a su pareja y no a la inversa, y son las mujeres 
las que más muestran sentimentalismo en cuanto a las relaciones amorosas, lágrimas y dolor frente a las rupturas, y no al contrario (p. 108).

Aunque el tema de la misoginia parece ser una exploración más abordada en el contexto norteamericano, por la crudeza con que la mujer es denigrada en las letras del hip hop/rap, vale la pena evaluar hasta donde, de modo semejante, habría manifestaciones de odio o menosprecio hacia las mujeres en otros géneros musicales a través de recursos más sutiles. Cuando, por ejemplo, se relatan decepciones sentimentales que nos sugieren la legitimación de formas de amar insanas (celos, apegos emocionales, locura, acoso, persistencia...) o nos presentan métodos de resolución de conflictos violentos entre las parejas de enamorados, que en algunos casos hasta demandan el castigo físico para aquellas mujeres cuyas actitudes y acciones se salen del "buen comportamiento" socialmente aceptado.

Bien lo plantearon Adams y Fuller (2006): "las ideas misóginas expresadas en la música no son un único o nuevo fenómeno" (p. 490) debido a que el mundo musical ha sido saturado desde siempre con imágenes e ideas como la de la mujer mala que echó al marido bueno, la interesada que se llevó el dinero de algún hombre o la traicionera que se acostó con el mejor amigo de otro.

Guarinos (2007), por su parte, considera que coexistiendo con canciones que explicitan y solicitan la violencia en contra de la mujer (aunque con menor frecuencia) también se observa en la industria musical la propensión de utilizar ritmos y melodías comerciales, y todo su circuito de promoción y ventas, para transmitir mensajes antisexistas o antiviolentos. No obstante, estas canciones comerciales de reivindicación contra los malos tratos de las que habla Guarinos, pueden llegar a caer en la paradoja de no ser escuchadas por reiteración de la emisión del mensaje. Queda, entonces, otro capítulo interesante al cual explorar: rastrear las imágenes positivas y los esfuerzos de hombres y mujeres detrás de los medios de comunicación por cambiar la tendencia hacia las asimetrías de género y las representaciones reducidas de la realidad social. Un capítulo que ojalá pudierámos reseñar con mayor frecuencia desde la academia, como el reflejo de una sociedad que está cambiando, en los planos real y simbólico, a favor de los derechos y las oportunidades de todos. 


\section{Referencias bibliográficas}

Adams, T. M., y Fuller, D. B. (2006). The Words Have Changed But the Ideology Remanis the Same: Misogynistic Lyrics in Rap Music. Journal of Black Studies, 36(6), pp. 938-957.

American Psychological Association (APA). (2007). Report of the APA Task Force on the Sexualization of Girls. Washington, DC 20002-4242 (202336-6044): Printed single copies available from: American Psychological Association Public Interest Directorate Women's Programs.

Arias Mendoza, D.,y Arroyave Cabrera,J. (2018). Representación mediática de la mujer en la oferta radial musical de Santa Marta, Colombia. Signo y Pensamiento, 36(71), 170-185. Recuperado a partir de: https://revistas. javeriana.edu.co/index.php/signoypensamiento/Article/view/21096

Aubrey, J. S., y Frisby, C. M. (2011). Sexual Objectification in Music Videos: A Content Analysis Comparing Gender and Genre. Mass Communication y Society, 14(4), 475-501. Doi:10.1080/15205436.2010. 513468

Balaji, M. (2010). Vixen Resistin': Redefining Black Womanhood in HipHop Music Videos. Journal of Black Studies, 41(1), 5-20.

Bandura, A. (1986). Social foundations of thought and action: A social cognitive theory. Englewood Cliffs, NJ: Prentice-Hall.

Baxter, R. L., De Riemer, C., Landini, A., Leslie, L., y Singletary, M. W. (1985). A Content Analysis of Music Videos. Journal of Broadcasting y Electronic Media, 29(3), 333-340.

Berrocal de Luna, E., y Gutiérrez de Pérez, J. (2002). Música y género: análisis de una muestra de canciones populares. Comunicar (18), 187-190.

Bohórquez, Á. (2008). Análisis de contenido de la representación de la mujer en la oferta radial musical de Barranquilla. Tesis de pregrado no publicada, Barranquilla, Colombia. 
Caplan, R. E. (1985). Violent Program Content in Music Videos. J O U R N A L I S M QU A R T E R L Y, 144-147.

Chaney, C. (2009). Trapped in the Closet: Understanding Contemporary Relationships in the African-American Hip Hop Community. Women y Language, 32(2), 59-67.

Click, M. A., y Kramer, M. W. (2007). Reflections on a Century of Living: Gendered Differences in Mainstream Popular Songs. POPULAR Communication, 5(4), 241-262.

Conrad, K., Dixon, T., y Zhang, Y. (2009). Controversial Rap Themes, Gender Portrayals and Skin Tone Distortion: Content Analysis of Rap Music Videos. Journal of Broadcasting y Electronic Media/, 53(1), 134-156.

De Lemus, S., Moya, M., y Bukowski, M. (2008). Activación automática de las dimensiones de competencia y sociabilidad en el caso de los estereotipos de género. Psicológica, pp. 115-132.

Donze, P. L. (2011). Popular music, identity, and sexualization: A latent class analysis of Artist types. Poetics, 39(1), 44-63.

Duany, J. (2010). Reggaeton. Caribbean Studies, pp. 182-185.

Emerson, R. A. (2002). "Where My Girls At?" Negotiating Black Womanhood in Music Videos. Gender y Society, 16(1), 115-135.

Fernández Poncela, A. M. (2005). Amor idealizado, llanto y traición en la canción romántica. Boletín Americanista (55), 101-122.

Frederickson, B. L., y Roberts, T. -A. (1997). Objetification Theory. Toward Understanding Women's Lived Experiences and Mental Health Risks. Psichology of Women Quartely, Cambridge University Press, 21, 137-206.

Frisby, C. M. (2010). Sticks 'n' stones may break my bones, but words they hurt like hell: Derogatory words in popular songs. Media Report to Women, 38(4), 12-18.

Gerding, A., y Signorielli, N. (2014). Gender Roles in Tween Television Programming: A Content Analysis of Two Genres. Sex Roles, 70:43-56. 
Gow, J. (1996). Reconsidering Gender Roles on MTV: Depictions in the Most Popular Music Videos of the Early 1990s. Communication Reports, 9(2), 151-161.

Guarinos, V. (2007). Mujeres de oidas. Las mujeres en la radio. Las mujeres en la música de consumo y el videoclip. En F. Loscertales, y T. Núñez, La Mirada de las Mujeres en la Sociedad de la Información (págs. 191-215). Madrid, España: Siranda Editorial.

Guarinos, V. (2011). La edad adolescente de la mujer. Estereotipos y prototipos audiovisuales femeninos adolescentes en la propuesta de Disney Channel. Comunicación y Medios, "Comunicación y edades de vida (II)" (23), 37-46.

Guarinos, V. (2012). Estereotipos y nuevos perfiles de mujer en la canción de consumo. De la mujer romántica a la mujer fálica. Cuestiones de género: de la igualdad a la diferencia (7), 297-314.

Hidalgo, M. B. (2010). Influencia de los estereotipos de género en la descripción psicológica de los personajes que aparecen en el texto de las canciones tradicionales. Revista de Educación, 213-223.

Horn Sheeler, K. (2007). Feminism for Stupid Girls: A Feminist Rhetorical Critique of a Popular Song by Pink. Conference of the National Communication Association (pág. 25). Chicago, IL: Feminist and Women's Studies Division Kristina Horn Sheeler.

Jhally, S. (Escritor), y Jhally, S. (Dirección). (2007). Dreamworlds 3: Desire, sex, and power in Music Video (DVD) [Película].

Krohn, F. B., y Suazo, F. L. (1995). Contemporany Urban Music: Controversial messages in Hip-Hop and Rap lyrics. Et xwrwe, 52(2), 139-154.

López Lita, R., y Bernad Monferrer, E. (2007). Publicidad, medios de comunicación y segregación ocupacional de la mujer. Revista del Ministerio de Trabajo e Inmigración, 213-226.

Martínez Noriega, D. A. (2014). Música, imagen y sexualidad:el reggaetón y las asimetrías de género. Cotidiano - Revista De La Realidad Mexicana, 29(186), 63-67. 
McClane-Bunn, A. D. (2010). Sex in the Hillbilly Field: Objectification of Women in Country Music Videos. Media Report To Women, 38(4), 6-11, 19-21.

Moody, M. (2011). A rhetorical analysis of the meaning of the "Independent woman" in the lyrics and videos of male and female rappers. American Communication Journal, 13, 43-56.

Muñoz, P. (2005). Las mujeres en las músicas populares. (U. A. México, Ed.) Convergencia. Revista de Ciencias Sociales, 12(37), pp. 361-374.

Railton, D., y Watson, P. (2005). Naughty girls and red blooded women. Representations of female heters. Feminist Media Studies, 51-63.

Seidman, S. A. (1992). An investigation of sex-role stereotyping in music videos. Journal of Broadcasting y Electronic Media, 36(2), p.209-216. 8p.

Signorielli, N. (2009). Race and Sex in Prime Time: A Look at Occupations and Occupational Prestige. Mass Communication and Society, 12, 332-352.

Signorielli, N., McLeod, D., y Healy, E. (1994). Gender stereotypes in MTV commercials: The beat goes on. The beat goes on. Journal of Broadcasting y Electronic Media, 38(1), 91-101.

Smith, S. L. (2005). From Dr. Dre to Dismissed: Assessing Violence, Sex, and Substance Use on MTV. Critical Studies in Media Communication, 22(1), pp. 89-98.

Sommers-Flanagan, R., Sommers-Flanagan, J., y Davis, B. (1993). What's happening on music television? A gender role content analysis. Sex Roles (28), 745-753.

Strasburger, V. C. (2004). Children, Adolescents, and the Media. Curr Probl Pediatr Adolesc Health Care, 54-113.

Strasburger, V. C. (2005). Adolescents, Sex, and the Media: Ooooo, Baby, Baby-a Qy A. Adolescent Medicine Clinics, 269-88, vii.

Strasburger, V. C. (2006). “Clueless”: Why Do Pediatricians Underestimate the Media's Influence on Children and Adolescents? Pediatrics (DOI: 10.1542/peds.2005-2336), 117; 1427. 
Strasburger, V. C., y Donnerstein, E. (1999). Children, Adolescents, ant the media: Issues and Solutions. Pediactrics, 103(1), 129-139.

Strasburger, V. C., Jordan, A. B., y Donnerstein, E. (2010). Health Effects of Media on Children and Adolescents. Pediatrics, 125(4), 125; 756.

Tanner-Smith, E. E., Williams, D. T., y Nichols, D. (2006). Selling Sex to Radio Program Directors: A Content Analysis of Radio y Records Magazine. Sex Roles, 675-686.

Turner, J. S. (2011). Sex and the Spectacle of Music Videos: An Examination of the Portrayal of Race and Sexuality in Music Videos. Sex Roles, 64:173-191.

Tyree, T. M. (2009). Lovin' Momma and Hatin' on Baby Mama: A Comparison of Misogynistic and Stereotypical Representations in Songs about Rappers' Mothers and Baby Mamas. Women y Language, 32(2), 50-58.

Wallis, C. (2011). Performing gender: A content analysis of gender display in music videos. Sex Roles(DOI: 10.1007/s11199-010-9814-2), 64:160-172.

Ward, M. L. (2003). Understanding the role of entertainment media in the sexual socialization of America youth: A review of empirical research. Developmental Review (Doi: 10.1016/S0273-2297(03)00013-3), 347-388.

Weitzer, R., y Kubrin, C. E. (2009). Misogyny in Rap Music A Content Analysis of Prevalence and Meanings. Men and Masculinities, 12(1), 3-29.

Wilson, J. (2000). "Women in country music videos". A Review of General Semantics, 57, 290-303.

Zhang, Y., Dixon, T., y Conrad, K. (2010). Female Body Image as a Function of Themes in Rap Music Videos: A Content Analysis. Sex Roles, 62 (Issue 11 -12), pp. 787-797. 